\title{
La herencia mexicana en la lucha sandinista de los años 20 en Nicaragua*
}

Michelle Dospital CNRS

A

unque ya existen algunos estudios sobre el movimiento de gua (1927Sandino, ${ }^{1}$ muy poco se conoce de la biografia del líder nicaragüense en la época anterior a 1927 y, en particular, durante su estancia en México de 1923 a 1926.

Reconstruir paso a paso el exilio de Sandino es bastante difícil. De las en-

- Título completo: La herencia mexicana en la lucha sandinista de los años 20 en Nicaragua. Experiencias políticas y sociales de Sandino en Cerro Azul (1925-1926).

${ }^{1}$ La lista bibliográfica es bastante importante por lo que sólo mencionamos algunas obras sig. nificativas: Torres, Sandino, 1984; Selser, Sandino, 1980; Román, Maldito, 1983; Instituto, Sandino, 1984; Dospital, "Mouvement", 1991. trevistas que dio el nicaragüense en los años 30, las alusiones a ese periodo de su vida fueron siempre evasivas $e$ in. cluso contradictorias. En cuanto a las personas que pudieron haberlo conocido, son pocas y sus recuerdos no son precisos. Pues, en ese momento, Sandino no era conocido, era muy poco hablador y no acostumbraba intimar con sus compañeros de trabajo.

Con el apoyo del Centro de Estudios sobre México y A mérica Central (CEM$\mathrm{CA})$, hemos podido realizar una investigación específica sobre este lapso de la vida de Sandino concentrando nuestros esfuerzos a partir de su llegada a Cerro Azul, población del estado de Veracruz, en donde trabajó como despachador de gasolina en la compañia norteamericana Huasteca Petroleum Co., desde agosto de 1925 hasta mayo 
de 1926. Encontramos interesante dicho periodo por varias razones:

1) Según algunos historiadores, fue en Cerro Azul donde Sandino se habría afiliado a la CGT, y sus planteamientos anarcosindicalistas habrian influido posteriormente en el pensamiento político del líder nicaragüense;

2) Ahí también fue testigo de la actitud nacionalista del gobierno de CaIles (1924-1928) ante las compañías extranjeras, la cual habría reforzado la posición política de Sandino en relación con los acontecimientos de Nicaragua.

3) Porque fue desde Cerro Azul y en ese momento de tensión política en México, que Sandino decidió regresar a su país después de seis años de exilio.

4) Por último, es el único lugar de México donde podemos confirmar la estancia de Sandino durante el periodo que nos ocupa. ${ }^{2}$

Para realizar este estudio, hemos consultado la biblingrafia relativa al pensamiento político de Sandino y a la vida política y sindical del estado de Veracruz, el Archivo General de la Nación, el Archivo General del Estado de Veracruz y hemos entrevistado a obre.

\footnotetext{
2 El 15 de marzo de 1928 , el gerente general cic la Huasteca Petroleum Co. mandó una carta a Harold Walker, vicepresidente de Pan A merican Petroleum y Transport Co. en Nueva York. la cual dice: "Sandino entró en la Huasteca el 17 de agosto de 1925 como empleads de nuest ro almacén en Cerro Azul, con un salario de 5 pesos diarios. Fl 1 de septiembre. fue promovido y tomó cargo del departamento de venta de gasolina de Cerro Azul con un salario de 6 pesos diarios. El 14 de mayo de 1926 , renunció repentinamente, declarando que tenia asuntos urgentes que resolver en Nicaragua. Fra trabajador, sobrioy aparentemente de buen carácter". Archivos del Instituto de Historia de Nicaragua, Managua.
}

ros petroleros y sindicalistas que trabajaban en los años veinte. El propósito de este artículo es describir las experiencias políticas y sociales que Sandino presenció en Cerro Azul y determinar las influencias que éstas tuvieron en su pensamiento político.

\section{LAS COMPAÑIAS PETROLERAS \\ Y LA CONSTITUCIÓN MEXICANA}

Con el fin de entender mejor el ambiente político y social en las compañías petroleras del estado de Veracruz en 1925, haremos referencia a dos artí. culos de la Constitución mexicana de 1917: El artículo 27, relativo a la propiedad de la tierra y el 123 , relativo a las condiciones socioeconómicas del trabajo.

Hasta entonces, la mayoría de las compañías petroleras norteamericanas despojaban inescrupulosamente de sus tierras a los campesinos comprándoselas a precios irrisorios o utilizando, a menudo, la tristemente famosa guardia blanca. Ante las leyes de 1917 los propietarios norteamericanos reaccionaron fuertemente, temiendo que esas disposiciones tuvieran una aplicación retroactiva en sus posesiones. La tensión alcanzó un nivel crítico cuando en 1921, el presidente Obregón quiso imponer una tasa de exportación al petróleo y replantear la legitimidad de los dere. chos adquiridos antes de 1917. El conflicto se resolvió con la firma de los tratados de Bucareli en 1923 y el restablecimiento temporal del statu quo.

En el aspecto laboral, además de una serie de regulaciones del trabajo, 
se reconocía a los trabajadores el derecho de sindicalización, de huelgas y de paro. Los conflictos se resolvían en la Junta de Conciliación y Arbitraje de cada estado, con una representación tripartita: gobierno-obreros-patrón. Después de varios congresos (1927, 1928, 1921), los sindicatos existentes se organizaron en dos centrales obreras: la CROM y la CGT. Esta última, de filiación anarcosindicalista, preconizaba la lucha de clases y excluía toda acción o colaboración política con el gobierno a fin de establecer el comunismo libertario. La CROM, de tendencia oficialista, tenía como principal objetivo defender los derechos laborales establecidos en la Constitución. Su política de colaboración oficial fue más evidente cuando el presidente Calles nombró a Luis Morones, dirigente de la CROM, como ministro del Trabajo en 1924.

En el estado de Veracruz, donde se concentraba la mayoría de las compa. ñias petroleras estadunidenses, existía un fuerte sentimiento antiyanqui. $\mathrm{Na}$ die había olvidado la ocupación militar del puerto de Veracruz en 1914. Se organizaron movimientos campesinos de resistencia apoyados por sucesivos gobernadores del estado: Adalberto Tejada (1920-1924) y Heriberto Jara (1924-1928). Ambos, de clara posición antiintervencionista, enfrentaron directamente las políticas de las compañías extranjeras.

Esta lucha fue a su vez sustentada por la lucha del movimiento sindical y sus reivindicaciones sociales. La organización sindical ya existía desde la segun. da década del siglo $\mathrm{Xx}$, en gran parte influenciada por los anarcosindicalistas. Después de la recesión económica de 1921-1923, según Miguel Ángel Ve. lazco, "el gobernador Tejada facilitó y promovió la organización de los sindicatos, los protegió y designó como inspectores del trabajo a compañeros que eran dirigentes sindicales a nivel regional". 3

\section{Sindicatos para la Huasteca Petroleum Co.}

En 1924, se habían registrado 33 sindicatos petroleros en el Estado de Veracruz, ${ }^{4}$ influenciados en su mayoría por la CGT, entre éstos el Sindicato Petrolero de Obreros y Empleados de la Huasteca Petroleum Co., establecido en la refinería de Mata Redonda. ${ }^{5}$ En sep. tiembre de 1924 este sindicato inició una huelga para su reconocimiento co. mo tal, un convenio colectivo de trabajo y aumentos salariales. Al ganar la lucha, el sindicato se extendió a ocho campos de la compañía. Entre ellos, Cerro Azul, donde estaba el pozo de mayor rendimiento, que llegó a ser la filial más importante. El gobierno de Calles aprobó una nueva ley con la idea de mantener una sola central sindical, decretando que sólo sería reconocido el sindicato con representación mayoritaria en la empresa. En el contexto legal y ante la

3 "Entrevista de Miguel Ángel Velazco", militante comunista, miembro fundador de la lunión de Panaderos de Jalapa, Estado de Veracruz, en los años veinte. 11 de mayo de 1993, México, D.F.

${ }^{4}$ Benitez, Organizactón, 1983, p. 91.

5 Para poder reconstruir la historia sindical de la Huasteca Petroleum Co., hemos consultado unos trabajos muy completos que son: Benítez, Organtzact6n, 1983; Alafita, "Trabajo", 1986; PEMEX, Mata, 1988. 
creciente popularidad de la CGT, la Huasteca Petroleum Co. promovió la organización de su sindicato blanco, el Sindicato Único, dirigido por el mismo jefe de la guardia blanca de la compañía.

El año 1925 se inició con una fuerte lucha proselitista entre los dos sindicatos para obtener el reconocimiento oficial. El sindicato de Mata Redonda reclamó la extensión de las condiciones del Convenio de septiembre a los otros campos de la compañía. Ésta rechazó la demanda y el sindicato declaró la huelga. Para entonces, marzo de 1925 , la superioridad del sindicato cegetista era evidente. Constituido en Federación con 3000 afiliados frente $\mathbf{6 5 0}$ del Sindicato Unico, fácilmente logró la generalización del paro por más de cuatro meses.

Con estos datos comprendemos por qué en algunos estudios se afirma que Sandino estuvo afiliado en el sindicato de la CGT de Cerro Azul. Sin embargo, sin excluir los posibles contactos que pudo haber tenido con algunos anarcosindicalistas de Tampico y Veracruz, mientras estuvo trabajando en Cerro Azul, Sandino no militô en las filas de la CGT por la sencilla razón de que, durante ese periodo, la Federación ya no existía... Lo que pudimos constatar es que él estuvo afiliado al Sindicato Único que, finalmente, había logrado ser impuesto por la compañía.

Al inicio de la huelga el Sindicato Único había solicitado apoyo a Luis Morones, quien ayudó entre otras cosas a la redacción de un Memorial dirigido al presidente Calles. ${ }^{6}$ Manipulan.

6 "Memorial del Sindicato Único al presidente Calles", 10 de marzo de 1925, AGN, ObregónCalles: caja 981, exp. 407 T13. do los objetivos de la lucha para encaminarlos hacia fines políticos, este Memorial denunciaba como origen del conflicto la supuesta acción agitadora de la CGT para la propagación de ideas bolcheviques. La Federación, apoyada por los gobernadores de Veracruz y Tamaulipas, refutó esta acusación y reivindicó los objetivos de la lucha: la extensión del Convenio de Mata Redonda y su reconocimiento sindical. En mayo, miembros del Sindicato Único asesinaron a un obrero cegetista. La Federación reforzó la huelga y exigió el despido inmediato de 14 miembros del otro sindicato. La tensión aumentaba, la posición del sindicato cegetista se mantenía inflexible y la compañía tampoco cedia. El presidente Calles declaró ilegal el paro, considerándolo como "un conflicto de índole personal", en lo cual coincidió con los petroleros extranjeros. Luego, se retiró de las conversaciones no sin antes haber hecho presión para que la Federación rompiera con la CGT y se adhiriera a la CROM.

En julio, después de tres meses de paro sin solución, la compañía publicó una lista del personal que estaba dispuesta a reenganchar sin represalias. Algunos obreros regresaron: 2000 huelguistas fueron cesados con $50 \mathrm{pe}$ sos y un pase de tren, después de confirmar en un recibo que ya no tenían ninguna relación con la petrolera. La Federación fue disuelta de facto. A fines de julio, la compañía ya había impuesto de nuevo la contratación individual: ${ }^{7}$ se consideraban tres días como periodo de prueba y después se

${ }^{7}$ Benítez, Organizactón, 1983. 
continuaba por tiempo indefinido. Se rescindía a voluntad de cualquiera de las partes ocho días antes, irrespetán. dose el artículo 123 de la Constitución que obligaba a la empresa a pagar tres meses de indemnización. A principios de agrsto, la compañía reconoció al Sir.cicato Único como titular del contrato de trabajo. Publicó la lista de trabajadores que necesitaba con las condiciones siguientes: contrato individual y afiliación al Sindicato Único.

El desenlace de la huelga significó un serio revés para el movimiento sindical: se perdió todo lo ganado en el año anterior. También fue una derrota para la CGT que, con ese conflicto, conoció el principio de la ofensiva que iba a enfrentar ante la CROM y el gobierno de Calles.

\section{SANDINO Y EL SINDICALISMO EN CERRO AZUL}

Fue en ese contexto de retroceso social y represión sindical que Sandino llegó a Cerro Azul el 17 de agosto de 1925. Para ser contratado, tuvo que afiliarse al Sindicato Único tal como lo exigía la compañía y como nos lo confirmó un compañero de trabajo de Sandino: David Brande. ${ }^{8}$ Por su parte, M. A. Velazco nos explicó que para ese entonces "los núcleos dirigentes de los sindicatos se convirtie. ron en monopolizadores del trabajo de tal manera que un obrero no podía entrar a trabajar sino a través del sin-

8 "Entrevista de David Brande", obrero petrolero de la Huasteca en Cerro Azul en 1925. Tampico, 9 de mayo de 1993. dicato, es decir a través de los líderes sindicales". Antes de esa fecha, el itinerario de Sandino en México es muy impreciso. Sabemos que a fines de 1923 él salió de Guatemala hacia Mé. xico, donde tuvo diferentes empleos: comerciante en la capital, obrero de la South Pennsylvania Oil Co. en Tampico y empleado de la PMF Co. en Álamo. De esos datos sólo tenemos confirmación del último por una carta que Sandino envió a su prima el 15 de marzo de $1925 .^{9}$

En el periodo en que Sandino trabajó en Cerro Azul, no se registró ningún movimiento huelguista en la compañía. De una manera general, la movilización sindical en las petroleras cayó en descenso ante las derrotas sufridas y la lucha de hegemonía entre las direcciones de los sindicatos. Sin embargo, aunque fue impuesto por la compañía y luego infiltrado por la CROM, el Sindicato Único mantuvo una lucha por la reivindicación común a todo el movimiento sindical, cualquiera que fuera su origen político: la del cumplimien. to de las leyes del trabajo del artículo 123 de la Constitución. M. A. Velazco insistió en que

la lucha por el cumplimiento de las leyes del trabajo era el motor principal, el motivo que condujo a los obreros a organizarse [...] Nuestra labor como sindicalistas era perseguir las violaciones a la ley, particularmente las violaciones a la jornada de ocho horas que, en muchas partes, no se respetaba.

9 "Carta de Sandino a María Mercedes Sandino", 15 de marzo de 1925. Dospital, "Mouvement", 1991, vol. 2, anexos. 


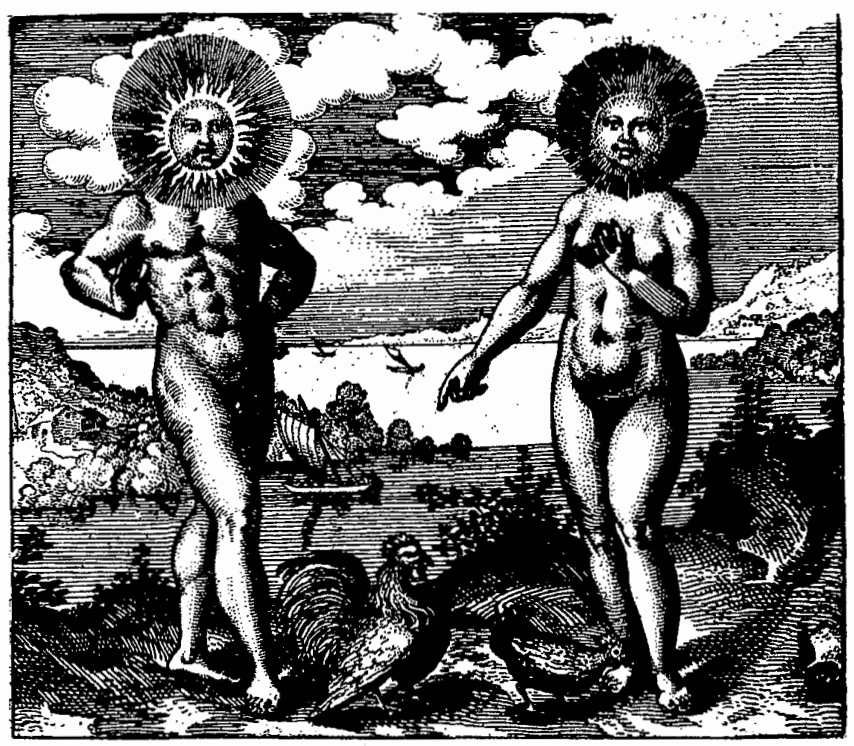

En el Memorial al presidente Calles, el Sindicato Único describía las conquistas sociales logradas en la compañia: un salario mínimo de 4 pesos, habitaciones cómodas, atención médica, caja de ahorros y escuelas para los niños en todos los campos. David Brande nos confirmó esta última información al precisar que, en Cerro Azul, la escuela para los trabajadores y sus hijos estuvo abierta a partir de 1925.

Como miembro del Sindicato Único, Sandino tenía la obligación de asistir a las asambleas. De los testimonios que recogimos, sabemos que el tema de esas reuniones giraba alrededor del cumplimiento de las leyes del trabajo. No pensamos que haya tenido más compromisos sindicales, pues según David Brande, Sandino era muy discreto, muy trabaja- dor, no se metía en nada y ni siquiera salía de paseo los fines de semana. Como lo veremos más adelante, lo que le causó más impacto de su experiencia en Cerro Azul fueron las regulaciones legales de las condiciones de trabajo y la lucha sindical para que éstas fueran respetadas por los patrones.

\section{El NACIONAIISMO DEL GOBIERNO DE CALLES}

Hubo otro acontecimiento político y económico que Sandino retuvo: el en. frentamiento entre el gobierno de Ca. lles y las compañias petroleras ante la nueva ley del petróleo en diciembre de 1925. Según ésta, las compañías debían solicitar al gobierno federal la 
confirmación de sus derechos sobre las propiedades adquiridas con antelación a 1917, así mismo estipulaba que las concesiones otorgadas a perpetuidad tendrían una vigencia restringida a 50 años. Las relaciones entre los gobiernos de Calles y de Coolidge, presidente de Estados Unidos, nunca fueron muy cordiales, pues el presidente mexicano había mostrado desde un inicio sus aspiraciones nacionalistas. El 31 de diciembre, Calles declaró en su mensaje anual a la nación que el sistema de reformas nacionalistas

no había sido inspirado por animadversión a extranjeros ya que, al contrario, se aceptaba la colaboración internacional para el desarrollo del país pero siem. pre y cuando ésta tenga por valladar res. trictivo el respeto a las leyes mexicanas [...] sin perjuicio de los intereses nacionales. ${ }^{10}$

El discurso se recibió como una bomba: varias compañías se negaron a acoger la nueva ley. El señor Doheny, dueño de la Huasteca Petroleum Co. fue su más violento opositor y amenazó con disminuir la producción y des. pedir a miles de obreros.

La actitud nacionalista de Calles recibió el apoyo del movimiento obrero de Veracruz donde, como ya lo vimos, el sentimiento antiyanqui era bastante fuerte. En ese mismo contexto, en el año de 1926, algunos compañeros de Sandino, al hablar de la sumisión de los pueblos latinoamericanos ante el imperio norteamericano, tildaron a los nicaragüenses de "vendepatrias". ${ }^{11}$ En

${ }^{10}$ Selser, Pequeño, 1984 , p. 56.

11 Roman, Maldito, 1983 , p. 56 octubre de 1925, el conservador nicaragüense Chamorro dirigió un golpe de estado contra el gobierno liberal; y el 2 de mayo de 1926, estalló una revuelta liberal en la costa Atlántica, conocida como la guerra Constitucionalista, para restablecer en el poder al gobierno derrocado. Entonces fue cuando desembarcaron los marines norteamericanos para "proteger las vidas e intereses de los ciudadanos ame. ricanos" residentes en Nicaragua. El 14 de mayo, Sandino presentó su renuncia a la compañía petrolera y regresó a su país.

\section{El regreso de SaNDino a Nicaragua}

El regreso "súbito" de Sandino tiene dos explicaciones. Tal como él mismo lo expresó en una entrevista con José Román, en esos seis años de exilio forzoso, su profundo anhelo era regresar a su patria, casarse con su prima y dedicarse al comercio. ${ }^{12}$ También en una carta de principio de mayo, su padre lo invitó a volver de nuevo a Nicaragua ya que las diligencias judiciales en su contra habian vencido y su novia lo estaba esperando. Según su hermano Sócrates, esa carta del padre pudiera haberlo convencido de que regresara. ${ }^{13}$ En la entrevista con Román, Sandino confiesa que, además, el motivo de su regreso tuvo que ver con las reflexiones de sus compañeros mexicanos, las cuales al herirlo en su honor lo habían decidido a ir a combatir en su país.

\footnotetext{
12 Ibid., p. 54.

13 Sócrates Sandino, "La vida del general Sandino", El Universal tlustrado, 23 de febrero de
} 1928. 
Las dos versiones no son contradic. torias: aun si su primera intención fue de regresar a instalarse en su pueblo natal, la suerte política de su país no le era indiferente: siendo adolescente ya era un fiel seguidor de su padre, connotado liberal y antiintervencionista. En 1912 quedó impresionado por el levantamiento liberal del general Zeledón quien fue asesinado por los marines norteamericanos, ${ }^{14}$ y luego, los acontecimientos políticos que presenció en México habrían reforzado, indudablemente, su sentimiento patriótico.

Al llegar a Nicaragua en junio de 1926 , Sandino no pudo quedarse en su pueblo. Se fue a San Albino, en Las Segovias del Norte, a trabajar en una mina de oro explotada por un norteamericano. A los pocos meses partió con 29 mineros y se alistó en las filas del ejército constitucionalista. El 4 de mayo de 1927 los liberales firmaron la paz con el enviado norteamericano Henri Stimson, aceptando el mantenimiento de las tropas de ocupación para "asegurar la paz y la estabilidad política". Sólo el "general" Sandino se negó a entregar las armas y dirigió, durante 7 años y desde Las Segovias, la más tenaz guerra de guerrilla contra las tropas de intervención de Estados Unidos en las primeras décadas del siglo XX.

14 En 1912, las tropas de intervención de Estados Unidos desembarcaron y mantuvieron ocupado el territorio de Nicaragua hasta 1924.

En una entrevista al Diarto de Yucatán, el 4 de octubre de 1929, Sandino declaró: “Zeledón, gran patriota, soldado valiente. Su heroico sacrificio en aras de nuestra soberanía no será olvidadon en Villanueva, Yucatán, 1988, p. 130.

\section{EL NACIONALISMO ANTIIMPERIALISTA DE SANDINO}

A pesar de la campaña antielectoral de los sandinistas, el liberal Moncada salió electo y tomó posesión de la presidencia de la República de Nicaragua el 1 de enero de 1929. Cinco días más tarde, Sandino presentó al presidente las bases de un convenio que, al ser aceptadas, permitirían alcanzar la paz y el reconocimiento del nuevo gobier. no. ${ }^{15}$ Este documento es el programa político más completo que él escribió. El primer eje de ese programa se refiere a la intervención norteamericana y a la construcción de un verdadero Estado nacional en Nicaragua. El general exigía el retiro de las tropas de ocupación, la anulación del tratado Bryan. Chamorro $^{16}$ y de todos los demás que habían sido celebrados a partir de 1909 , el rêchazo a cualquier "empréstito yanqui" y la condenación de la deuda del gobierno nicaragüense con el de Estados Unidos pues "la nación no tiene por qué pagar con sus recursos los experimentos que el gobierno de Estados Unidos ha mandado a realizar de sus modernos equipos bélicos en los

15 "Bases del convenio que se propone al general José María Moncada para que se constitucionalice como presidente de la república de Nicaragua en el periodo de 1929 a 1932", 6 de enero de 1929. Instituto, Sandino, 1984, vol. 1, p. 297.

16 El 5 de agosto de 1914, el general nicaragiiense firmó con el secretario de Estado de Estados Unidos, William Bryan, un tratado cediendo por tres millones de dólares una zona del territorio nicaragüense para la construcción de un canal interoceánico, las islas del Maíz en arriendo por 99 años y el derecho de establecer, explotar y mantener una base naval en el golfo de Fonseca. 
pechos de los patriotas nicaragüenses". Además, Sandino pedía que el presidente proclamara la Unión Centroamericana e invitara a todos los gobernantes de la América Indo Latina, Continental y Antillana a una asamblea, a fin de organizar una confedera. ción de todos estos pueblos, formando así un frente único capaz de contra. rrestar el avance del imperialismo norteamericano.

Esas reivindicaciones fueron la médula de la lucha sandinista y del proyecto político de su jefe. Como se puede observar, el campo de la lucha antiimperialista consideraba la dimensión militar, política y financiera. En ese documento, la referencia a la intervención económica es más indirecta. Al hablar de la construcción de carreteras y ferrocarriles que había prometido el presidente Moncada, Sandino decía que

no les importaría a los nicaragüenses, supuesto que los beneficiados serían solamente las compañias extranjeras, únicas y verdaderas aprovechadoras de dichas construcciones, porque no ignoramos que el gobierno de Nicaragua tiene comprometidos con los yanquis hasta los taburetes de los edificios públicos.

El interés de Estados Unidos por Nicaragua no era tanto económico como geopolítico: una vez comenzada la construcción de la vía interoceánica en Panamá en 1904, la mayor preocupación política de Estados Unidos fue impedir que Nicaragua pudiera conceder a otro país los derechos de construcción de un nuevo canal. Para ese fin se sirvieron de la llamada "diploma- cia del dólar" para controlar políticamente al país.

En 1924, los banqueros controlaban todas las fuentes de los ingresos estatales: las rentas aduaneras, los impuestos de exportación e importación y el Banco Nacional, llegándose al extremo de que el presupuesto de gastos anuales del gobierno de Nicaragua era fiscalizado y aprobado por los acreedores norteamericanos. En cambio, en los años veinte, el valor total de las empresas norteamerica. nas en Nicaragua era alrededor de seis millones de dólares repartidos en plantaciones bananeras y cafetaleras, compañías madereras y minas, lo que era insignificante en relación con las inversiones norteamericanas en los paí. ses vecinos.

Fue este objetivo político de Estados Unidos el que Sandino denunció y contra el que luchó prioritariamente. Cuando el general Sandino tomó como blanco a las compañías norteamericanas, sus represalias militares tenían ante todo un objetivo político: probar la inutilidad de la intervención del gobierno de Estados Unidos, demostrando que los marines eran incapaces de proteger a sus connacionales en Nicaragua.

En contadas ocasiones Sandino trató el aspecto económico de la intervención. No sólo porque las propieda. des norteamericanas eran pocas sino también porque, en ese momento como él mismo lo expresara más tarde, no existía en Nicaragua problema de tierras. En 1920, de las tierras cultivables que constituían las dos terceras partes del territorio, sólo $5 \%$ servían a la agricultura y $3 \%$ a la ganadería. Más 
del $50 \%$ de estas tierras cultivables eran aún selvas.

Aunque la lucha nacionalista y antiimperialista en México y Nicaragua tenía el mismo objetivo, el de construir el Estado nacional, no podía realizarse de la misma manera por la diferencia de contexto político, económico y social en cada país. La lucha contra las compañias extranjeras que se llevó a cabo en México no tenía cabida en $\mathrm{Ni}$ caragua, Sandino estaba consciente de esa realidad. Sin embargo, su experiencia en México le permitió prevenir lo que podría ocurrir en su patria y es así como, en 1933, se declaró partidario, en una entrevista, de la nacionalización del suelo y del subsuelo así como de la inversión de capital extranjero siempre y cuando se sometiera a las leyes del país y no explotara a los trabajadores. ${ }^{17}$ Esta posición nos recuerda la del presidente mexicano Calles y, en particular, su discurso del 31 de diciembre de 1925.

En 1929, Sandino confesó que su lucha había seguido "el ejemplo de los patriotas mexicanos, en cuyos hechos gloriosos mi espíritu y mi ideal han encontrado siempre una fuente de inagotables recursos y un caudal de vigorosa inspiración para la lucha". ${ }^{18}$ Pensamos que lo que él rescató de su experiencia mexicana fue una actitud

17 "Conversaciones con Belausteguigoitia", 4 de febrero de 1993. Instituto, Sandino, 1984, vol. 2 , p. 294 .

18 "Carta a Emilio Portes Gil", 30 de julio de 1929. Ibid, vol. 1, pp. 364-365.

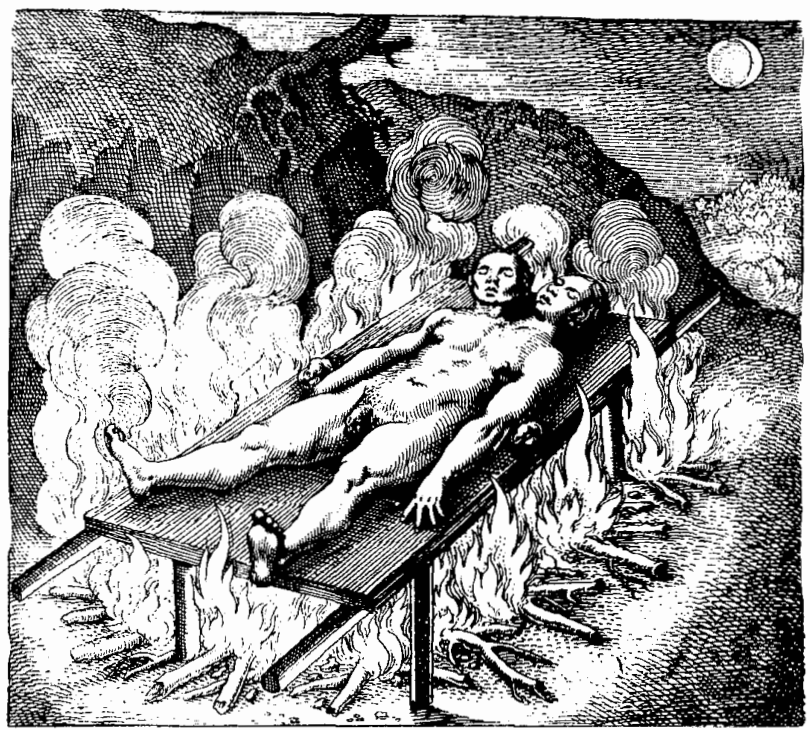


que significaba: dignidad nacional, patriotismo y antiimperialismo, así como la lucha política de los gobernantes por el respeto a la Constitución.

\section{Legislación del trabajo}

El segundo eje del programa sandinista de 1929 se refiería a la legislación del trabajo. Se trataba de una serie de medidas concretas: la jornada máxima de ocho horas, leyes sobre accidentes de trabajo, salario especial en horas extras, salario en moneda efectiva y supresión de los "vales", instrucción primaria obligatoria para los trabajadores en las empresas, igualdad de salario para la mujer, regulación del trabajo de los niños, derecho de organización y de huelga para los trabajadores y creación de un Departamento Nacional del Trabajo encargado de regular las relaciones entre patrones y trabajadores.

La primera acción de Sandino, en mayo de 1927, fue ocupar la mina de San Albino y distribuir el oro entre los mineros. Justificó su acción acusando al empresario Chas Butter de ser

un defraudador del salario de los trabajadores a quienes obliga a trabajar 12 horas diarias pagándoles con vales, los cuales son aceptados solamente en su comisariato a cambio de mercaderías a doble precio. 19

En Nicaragua, no existía ninguna legislación del trabajo. Tampoco exis. tían organizaciones sindicales en el campo, excepto unas cuantas en la

19 "A mis compatriotas nicaragüenses", 14 de julio de 1927 , ibid, vol. 1, p. 124. costa atlántica. Al experimentar las vergonzosas condiciones de trabajo en su país y recordar las que había vivido en México, Sandino se indignó e, inspirado en la Constitución y las luchas sindicales mexicanas, propuso al presidente Moncada un proyecto de leyes del trabajo bastante completo $y$ en muchos aspectos, similar al artículo 123 de aquel país.

Para la Nicaragua de 1929 era un planteamiento revolucionario pero también anacrónico. La industria aún no existía, con excepción de dos re. finerías de azúcar y pequeñas empresas artesanales. Las pocas organizaciones sindicales existentes en la ciudad agrupaban a artesanos y co. merciantes y eran más bien asociaciones mutualistas que seguían los lineamientos de los partidos políticos tradicionales. En el campo, exceptuando a las compañías madereras y bananeras y a las minas, la mayoría de los trabajadores asalariados eran cam. pesinos semiproletarizados. Habría que esperar, en los años 50, la introducción del algodón para ver el despegue del desarrollo industrial $y$, por consiguiente, la formación de un verdadero proletariado rural.

A medida que fue avanzando la lucha, Sandino comprendió que el combate por lograr que se dictaran leyes del trabajo, si bien era fundamental en el México de los años 10, no era prioritario en la Nicaragua de los años 20. En los hechos, él seguirá defendiendo las reivindicaciones sociales, ocupando las compañias extranjeras, distribuyendo la comida de los comisariatos entre los trabajadores y creando un departamento docente de 
la guerrilla, mismo que se encargó de enseñar a leer y a escribir a los soldados e incluso de organizar escuelas en los pueblos indígenas de las orillas del río Coco. Pero a partir de 1930 , con la radicalización de la contienda militar, el programa político estableció como segundo eje, después de la lucha antiimperialista, la reivindicación de las demandas de la base fundamen. tal del movimiento sandinista, la gran masa campesina: preservación de sus propiedades y acceso al usufructo de las tierras nacionales.

Es poco probable que podamos llegar a conocer todo lo que Sandino experimentó en sus seis años de exilio, particularmente en México. Más importante históricamente es llegar a descifrar los elementos de su pensamiento político que pudieron haber tenido origen en los acontecimientos presenciados en su exilio mexicano. Los dos ejes analizados, del programa político de 1929, nos parecen fundamentales; no sólo porque ponen de relieve la influencia que tuvo la revolución mexicana sino porque también nos muestran cómo Sandino supo adaptar e incluso reorientar las ideas recibidas a la situación particular de su país.

En cuanto al tema nacional, lo que Sandino captó en México fue, como dije, la actitud de sus gobernantes, su capacidad de enfrentar la intervención extranjera y de hacer respetar la Constitución. De todos los gobiernos nicaragüenses, sólo uno había adoptado una actitud similar: el gobierno del liberal Zelaya (1893-1909). Los demás se sometieron interesadamente a las directivas del gobierno norteame- ricano. Durante los seis años de guerrilla, el general siempre reivindicó que la construcción del Estado nacional de Nicaragua reposaba en un gobierno legalmente electo, respetuoso de la Constitución, nacionalista y antiimperialista. Esa era la esencia de la lucha política de Sandino.

En el campo social, consciente del atraso a que estaba sometido su país, trató de introducir los avances sociales que había experimentado en México en cuanto a legislación del trabajo. Pero el terreno social, en el que se desarrolló la lucha sandinista, llevó a su jefe a reorientar su programa hacia reivindicaciones campesinas y no obreras, más acordes con la realidad socioeconómica de Las Segovias.

En cuanto a la posible influencia de los anarcosindicalistas mexicanos, no encontramos ningún planteamiento común entre ellos y el programa politico de Sandino; quizá podamos hablar de contradicciones, ya que ellos preconizaban la supresión del Estado mientras él luchaba por su reforzamiento.

Sin embargo, sería interesante analizar el proyecto de colonia agrícola autogestionada que Sandino creó en Las Segovias después de la firma de la paz en 1933. Esa "sociedad de ayuda mutua y de fraternidad universal ${ }^{\prime}, 20$ respondía al proyecto del espiritista argentino, Joaquim Trincado, fundador de la Escuela Magnético-Espiritual de la Comuna Universal (EMECU) y fue en México, en 1929, donde Sandino se adhirió a esa escuela. La pregunta

20 "Carta a Alfonso Alexander", 7 de julio de 1933. Dospital, "Mouvement", 1991, vol. 2, anexos. 
que nos suscita es, si existía o no diferencia entre el "comunismo libertario" anarquista y el "comunismo racionalista" de la EMECU que defendió Sandino. ${ }^{21}$

\section{BiBLIOGRAFIA}

-Alafita Méndez, Leopoldo, "Trabajo y condición obrera en los campamentos petroleros de la Huasteca, 1900-1935", Anuario IV, Centro de Investigación Histórica de la Universidad Veracruzana, Jalapa, 1986.

-Benítez Juárez, Mirna, Onganización $y$ lucha sindical de los petroleros en Veracruz, 1918-1928, Facultad de Sociología, Jalapa, 1983.

-Dospital, Michelle, "Le mouvement

21 "Mientras usted huye llamarse comunista, yo to declaro al Universo entero, con toda la fuerza de mi ser, que soy comunista racionalista". "Carta a Humberto Barahona", 27 de mayo de 1933. Instituto, Sandino, 1984, vol. 2, p. 338. sandiniste de libération nationale au Nicaragua (1927-1934). Essai d'analyse d'un projet politique", tesis de doctorado, Estudios hispánicos e hispanoamericanos, 2 vols., Universidad de París VII, 1991.

-Instituto de Estudios del Sandinismo, A.C., Sandino. El.pensamiento vivo, introducción, selección y notas de Sergio Ra. mírez, 2 vols., Nueva Nicaragua, Managua, 1984.

-PEMEX, Mata Redonda y Cerro Azul. Dos historias en torno al petróleo. 1900 . 1938, México, 1988.

-Román, José, Maldito país, El pez y la serpiente, Managua, 1983.

Selser, Gregorio, Sandino, general de nombres libres, EDUCA, San José, 1980.

, El pequeño ejército loco, Sandino y la operactón México-Nicara. gua, 2 vols., Nueva Nicaragua, Managua, 1984.

-Torres, Edelberto, Sandino, Realidad Social, Managua, 1984.

- Villanueva, Carlos, Sandino en Yucatán (1929-1930), Secretaría de Educación Pública, México, 1988. 


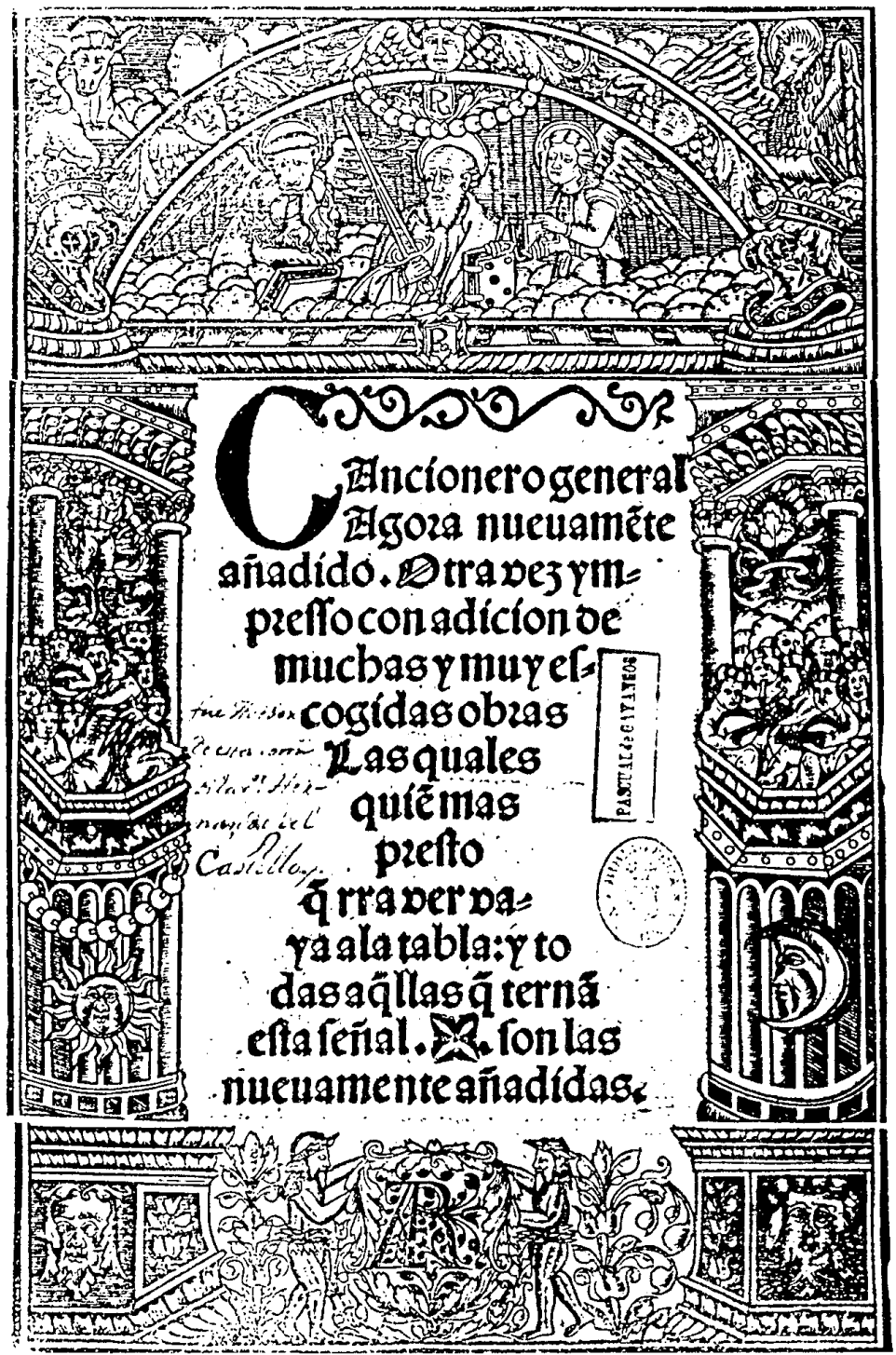

